\title{
FORECASTING SOCIAL MEDIA AS POTENTIAL TOOL FOR TEACHING AND LEARNING PROCESS IN THE CLASSROOM
}

\author{
Harisa Mardiana \\ Fakultas Sains dan Teknologi, Universitas Buddhi Dharma \\ JI. Imam Bonjol No. 41, Tangerang, Indonesia \\ Email: harisa.mardiana@buddhidharma.ac.id
}

\begin{abstract}
To pursue the ability and excellence in competing in the education sector, teaching and learning process have to come ahead of time. It means they the produce of innovative learning process which responds to campuses, students and lecturers need on a regular basis. Social media offers the insight which is required to make prediction of future education. By using social media, students and teachers can ask and response the learning process immediately. We need to pay attention of complexity of education as it can present various obstacles. Diverse data processing methods need to be applied in order to have $21^{\text {st }}$ century meaningful and useful. The purpose of this paper is to review the forecasting of social media as a tool in teaching and learning process. The study is conducted on the basis of a critical literature review in order to give a clear impression of the potential and the value of Social Media data for forecasting purposes. It was found that social media can be a tool for teaching and learning process. However it has to be cautious due to numerous limitations of social media and teaching and learning process methods which have to be applied. Furthermore since the topic of forecasting social media as a tool, campuses, lecturers and students need to use social media has not been addressed specifically. This paper establishes a new framework tailored for predictions regarding future good education systems, professionalism for lecturers which support the process of prediction are identified.
\end{abstract}

\section{Keywords}

Forecasting, Social Media as a tool, Innovation, Teaching and learning Process

\section{Introduction}

As predictive tools, social media in academic environment is quiet fresh to use and many different outcomes which is briefly being drawn. As the learning process is an ingrained part of today's society and the social media can be a tool for teaching and learning in the classroom. In digitalized world, all data are appeared and material, methods or everything about education can be seen in the internet. According to Gundecha \& Liu, (2012), that Social media gives users an easy-to-use way to communicate and network with each other on an unprecedented scale and at rates unseen in traditional media. As a platform, social media involved in many activities in human life, and participate in education to contribute itself and has a channel and boundaries. Education itself is the process of receiving or giving systematic instruction which usually does it in the school or university. To enlightening the experience in patience and forbearance, the teaching in the classroom must have a system that make a boundary between teacher and students to follow the rules.

Estimating the students' lifetime value is relatively straightforward which they use social media in their lifetimes will contribute the process in teaching and learning over some period of time, and then projecting that pattern forward over some future period of time using sophisticated model of learning [1]. Students usually rely on personal advices, recommendations and suggestions from teachers, scholars or friends to make a decision.

This personal informal of exchanges communication that students share with one another often refer to as word-of-mouth. WOM often takes the form of objective product information in addition to subjective personal opinions and experiences [2]. Social media 
Akselerator

Jurnal Sains Terapan dan Teknologi Vol.2 No.2 December 2017

engages in learning process by helping to make the students aware of current happenings, concerning to the learning process and having a social activity at the same time. To forecast social media as potential tool, this journal article is concerned in reviewing the teaching and learning process, conducted on the basis of critical literature review in order to give a clear picture of potential and valuable of social media which Barakos, Constinides \& Loohuis (2015) conducted that on extending the knowledge of the forecasting is the purpose as a learning tools and the power of social media and gain insight into discovering the value of teaching and learning process. It is cautious due to numerous limitations of social media forecasting in teaching and learning methods which have to be applied. Hence the following questions will be addressed:

What is the value and potential of social media generated to organizations for the purpose of predicting future education?

\section{Theory and the Applicable of Forecasting Social Media}

The word of forecast means the process of making prediction of the future based on past and present data and most commonly by analysis of trends [3].The example of estimation from some variable of interest at some specified future date is more general term to formal statistical methods or alternatively to less formal judgmental methods. The use of forecasting can be totally different between areas of application. It is sometimes reserved for estimates of values at certain specific future times. (p.2). The power of prediction of social media has become a much-talked about topic in the previous couple of years with increasing popularity focusing on different aspects such as predicting election, the stock market, diseases and many other variables.[4]. The mechanism of forecasting of social media data could potentially be an enormously valuable tool to organizations if it is handled appropriately and it could deliver a competitive advantage as it can convey insights into efficiently meeting constantly changing consumer desire, communicated through Social Media.[5]. The methods of forecasting may be divided into two major classes. (1) uses primarily an empirical approach and (2) combines other theory such as economic theory with empirical evidence. The best known empirical approach to forecasting is the leading indicator technique. This was originally developed by the National Bureau of Economic Research (NBER) during the 1920s and since 1961 data for applying this technique have been published monthly [6].

Social Media as a tool is particularly useful to assess connectivity between groups. It can provide insight into which members are connected to each other, their level of collaboration and the overall network health in terms of information flow. Social media gives users an easy-to-use way to communicate and network with each other on an unprecedented scale and at rates unseen in traditional media [7]. As a category of online discourse, in social media, people create content, share, bookmark and network at a prodigious rate, because its ease of use, speed and reach, social media is fast changing the public discourse in society and setting trends and agendas in topic that range from the environment and politic to technology. [5]. In education especially in campuses, it seems that some lecturers are indeed beginning to tap into the potential benefits of social media. The use of social media helps the teaching and learning better and it is shown on figure 1. 


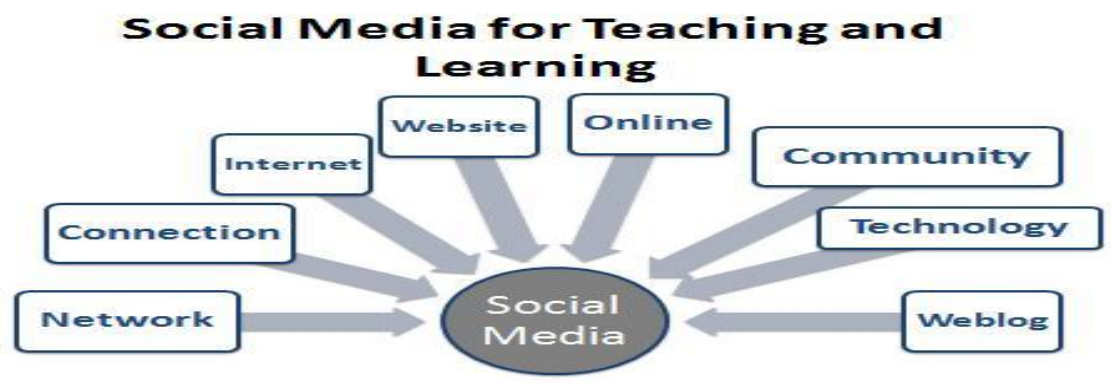

Figure 1. Social Media for Teaching and Learning category of online and create content, share, bookmark and have the network at the prodigious rate. ([5]

Many faculties and societies have attuned to the fact that $75 \%$ of students admit to being on Twitter and Facebook all the time are using the micro-blogging site as a forum to share content, encourage debate and answer queries, with setting up hash tags for individual courses to create online discussion communities for students. [8]. And indeed, it is a strategy believed that some lecturers provoke more thoughtful responses from students and the idea being comments and can be read by peers and not just by the lecturer, so it may consider that it says it is carefully more pay attention to how they write it and take more care with grammar, spelling and punctuation. Social media is virtual communities which its social aggregation that emerge from the loosely connected computer network when enough people carry on those public discussions long enough with sufficient human feeling to form webs of personal relationships in cyberspace. [9]. According to Boyd \& Ellison (2008), social media sites as web-based services that allow individuals to: (1) construct a public or semipublic profile within a bounded system; (2) articulate a list of other users with whom they share a connection; and (3) view and traverse their list of connections and those made by others within the system and Kaplan \& Haenlein, (2010) introduced seven building blocks for social media identity, presence, relationships, reputation, groups, conversation and sharing. The seven building blocks is shown on figure 2 .

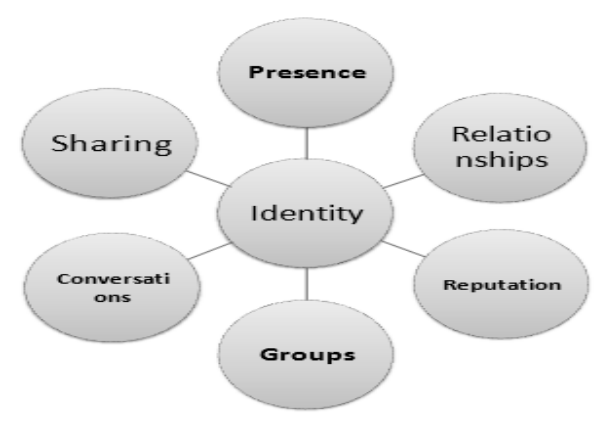

Figure 2. Seven Building Blocks of Social Media which the users reveal all of the seven building. [10]

The seven blocks is indicated to Identity, this is the extents to which the users reveal them; presence is extent to which the users know if others are available; relationships is the extents to which users relate to each others; reputation is the extents to which the users know the social standing of others and contents; groups extents to which the users are ordered or form communities; conversations is the extents to which the users communicate with each others; sharing is the extent to which the users exchange, distribute and receive contents (p. 4). Another scholars Bertot, et., al. (2012), noticed that social media is relatively new term, but the idea of applying online tools to facilitate social interaction was elaborated 
long ago. Predecessors of social media are email lists, Usenet, and bulletin boards. However, there is a question that social media could play a more central role in university education and what the future may hold. It means social media can change the education and the content is produced on social media is especially useful due to the context of the study. Asur \& Huberman, (2014) claimed that social media is fast, changing the public discourse in society and setting trends and agendas in topics that range from the environment and politics to technology and the entertainment industry. Facebook and Twitter might produce different enough discussion platform that those with minority views might feel freer to express their opinions, thus broadening public discourse and adding new perspectives to everyday discussion of political issues. [11]. The range of topics and interests with the large geographic scope make it possible of campuses to analyze every type of industrial sector, country, gender, personal profile and any other attribute in which they wish to expand their knowledge and expertise. [12].

\section{Method of Social Media as an Innovation Tool of Teaching and Learning Process}

This paper is to accumulate a range of relevant literature and opinions regarding the issue of Social Media platform as a predictive tool, in order to reach clear and straightforward conclusions, to fill the gap of knowledge and to provide a general overview concerning this field of knowledge. The criterion for the paper selection was the focus of referring to Social Media such as Twitter, Facebook or any other platform as a predictive tool. The articles used in the literature review are derived from electronic search engines, primarily Google Scholar, as well as online library. Also, the paper includes the innovation as one of the forecasting tool for teaching and learning process. As we know, an Innovation occurs when the entity or person makes significant contribution to a product or service that is already known and is one of the primary ways to differentiate the product or service from competition. [13]. The use of innovation comes when a social system's norms favor change, opinion leaders are more innovative, but when the norms do not favor change, opinion leaders are not especially innovative. [14].

The teachers and campuses can elaborate themselves by using social media in the classroom. Social media can be a tool to complement effective teaching strategies that encourage students to practice reflexive, communicative, critical thinking and problem solving skills in collaborative environments. Particularly, such as Facebook, Twitter and other social media are changing the attitudes and behavior related to information and learning. [15]. Witek \& Grettano (2014) identified that four effects of social media use on students' behavior and learning practices, namely: "Information now comes to users" - manifested mainly through the feed functionality of Facebook; "Information recall and attribution are now social" - students categorize information based on who shared the information with them; "Evaluation is now social"- the value of information students encounter online is directly related to how others in their networks value that information and whether the information is relevant to their friends; "Information is now open" - Users within participatory information environments are both publishers and authors simultaneously. Their information literacy practices are constantly on display and thus shaping their visible identities. The figure for methodology of social media as an innovation tool is shown on figure 3.

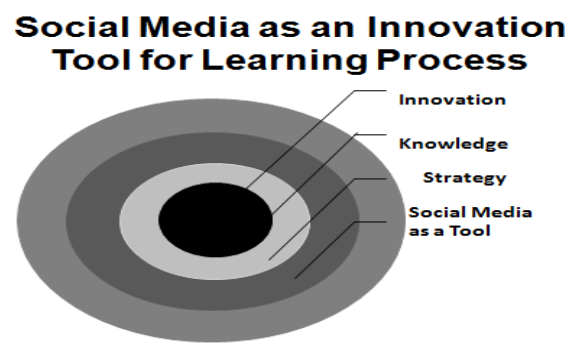


Akselerator

Jurnal Sains Terapan dan Teknologi Vol.2 No.2 December 2017

Figure 3. Social Media as an Innovation Tool for Learning Process which connected with topic in previous years and valuable resources and information exchange (Dunbar, et., al. (2014)

As a forecasting tool, social media has been a significant, widespread topic in previous years, plenty of definitions are available. [2]. Valuable resources and information flow through the networks in various ways, often prescribed path or hierarchy. The effect of the network on culture and learning can be significant, as culture and learning improve the speed and efficiency of information exchange. [16]. By deliberately facilitating connections, the network can drive the teaching and learning goals and improve strategic decisionmaking. The figure for forecasting social media as a tool is shown on figure 3.2.

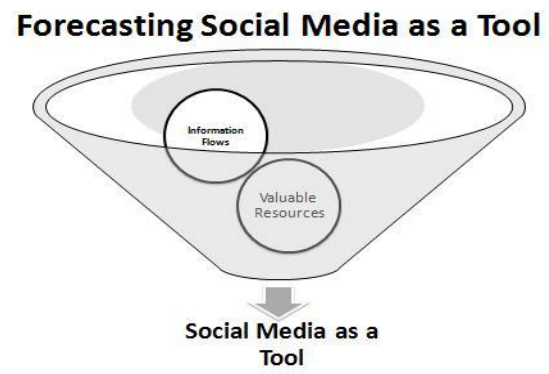

Figure 4

4. Forecasting Social Media as a

Tool to construct the information flow through the network on culture and learning process. [17]

In social media, there are two significant constructs, density and diversity and both of them can be influenced by teaching and learning process to drive a given education outcome, dense network tends to have increased level of cooperation and faster rates of knowledge transfer and diverse network describe structures that have connections to broader, more distant individuals and groups (p.4). Both networks assure a flow of new information and are linked to innovation also tend to be more efficient in terms of knowledge transfer due to a larger diffusion of information and less redundancy [17].

\section{IResult}

\section{The Process of Forecasting Social Media as a Tool in Teaching and Learning}

There has long been the pervasive notion that learning can take place only in the classroom. Classrooms are designed to focus attention, close off the rest of the world, and create a controllable environment where learning can take place. And the classroom remains the dominant central fixture of today's education systems. [18]. But, since social media introduced to the education systems, learning process will not take only in the classroom, but it takes everywhere in 24 hours. In the classroom, the use of social media as a learning tool allows for the strengthening of relationships, sharing of ideas and creating industry contacts. All students and teachers encouraged connecting to Facebook or Twitter or other social media, whist in a few hours the students posted over the following week and the exercise created a distinct sense of community and space which to share the ideas in a casual, easily accessible format that isn't restricted by the rigid expectations of university platforms [17]. Social media is an effective way to increase student involvement and build better interaction skills. Learners who hardly ever raise a hand in class may feel more comfortable on Facebook, Twitter, or YouTube. Social media systems enable instructors to identify "back channels" that promote conversation and surface ideas that students are too shy or nervous to speak out in class.[19]. The value and potential of social media to predict future education 
will lead to advance of source attitude on the technical side of education and it contributes the service of teaching and learning. The attitude of learning is changed and the benefit of communicating via social media as a questions or comments, sharing information and garnering feedback will be quicker than when the learning process in the classroom [20]. Social networking practices have the potential to be effectively applied in teaching and learning and bring about advantages in learning. Godwin (2009) for example, pointed on the potentials Web 2.0 environments for active, collaborative and reflective learning and integrating these innovative and contemporary practices seems to be a slow process that is likely to encounter resistance by educators due to their previous experience as traditional learners and teachers. By implementing networking practices, the necessary skills will be developed for students and teachers to pursue the integrated social media in teaching and learning process. This element emphasizes the student's life as being an intrinsic dimension of their formal engagement with their course and emphasizes ideas found in constructivist theory about building on what already exist [21]. By having a life wide appreciation of learning, the campus is able to think more broadly about the student's environment and how each student is able to arrive at significant learning points in their own way and within the context of their formal course (p. 48). In collaborating social media and networking, sharing knowledge and content and all of the features are of great value in the context in education [22]. Many campuses have well-developed social media strategies, and use a suite of social medial tools for various purposes including internal and external communication,

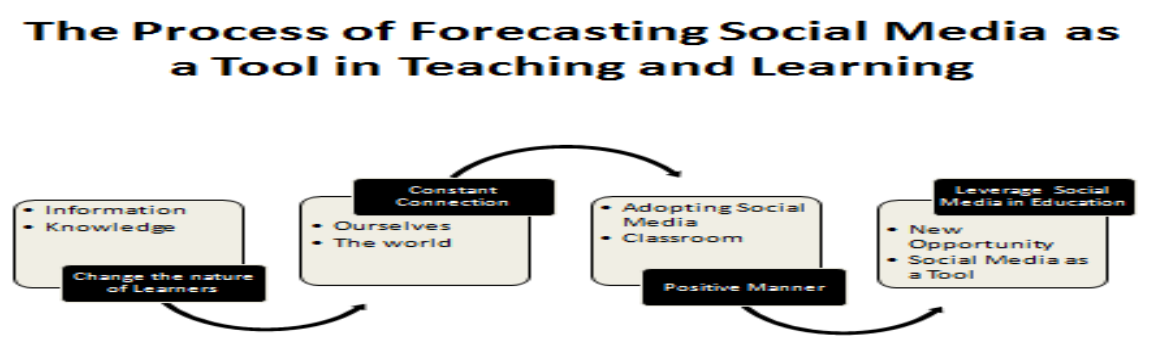

recruitment, sharing research findings and highlighting exciting students initiatives [23]. The process of forecasting social media as a tool in teaching and learning is shown on figure 5 .

Figure 5. The Process of Forecasting Social Media as a Tool in Teaching and Learning [23]

However, in recent years, learning management systems such as Moodle and Blackboard have become immensely popular in universities as means to distribute teachers notes and other course information, as a portal for students to upload assignments and check them for plagiarism, and as chat forum where students can communicate with their teachers and each other, the platforms allow for easy integration with social media services 
Akselerator

Jurnal Sains Terapan dan Teknologi Vol.2 No.2 December 2017

so that the teachers and push content automatically to apps like Twitter, Facebook or else. [24]. So, what the future may hold if social media use as a tool for education? With the lead of distance learning models, which provides to oblige the nature of the courses to keep pace with any trends and technological advances, it will have promoted of communication with students and enhance the learning experience. [25]. In embracing technologies of cooperation, prototyping new models of learning process, and cultivating open and collaborative approaches to leadership, social media will challenge the institutional hierarchies and policies to provide the exemplar of innovation to the learning programs.

\section{Discussion}

\section{The Potential of Social Media as a Tool for the Purpose Future Education}

The major force of transformation in future education will change and shape the effort to remake learning. The drive of change, along with related trends and signal, appear on the inside of forecast. [26]. Considering to the implication for the future of learning, it is found with helpful driving force to the $21^{\text {st }}$ century of education. The need for schools and centers learning and the broad of community will emphasize on the need of ongoing process of education (p. 12). Students and teachers and campuses engage full time and globally. The forecast illuminates the vital need for everyone concern about learning, not only the education such as teachers, students and campuses, but also the powerful innovators on the periphery actively creating the future of learning. The ability to meet the social, economic, health and climate challenges of the next several decades depends on the heeding these messages from the future.[27]. It is mentioned that social media offered avenues to engage the students and a way in which online students in particular can easily connect with academic staff and each other. In the classroom, the use of social media as a learning tool allows for the strengthening of relationships, sharing ideas and creating contact with others such a teachers, scholars. New challenges of learning are emerging and will affect societies and countries around the globe. (p. 34). The need to innovate and modernize school education to adequately prepare students for the future together with learning will be more tailored to the needs of individuals and actively re-integrated into real life [17]. The main objectives of the future education are to identify, understand and map of learning strategies and trajectories are expected to change, given current trends, thus creating a descriptive vision of the future, by identifying key challenges and strategies which ensure that future learning opportunities contribute to social cohesion, socio-economic inclusion and economic growth.[28]. As the purpose of this paper is to review the forecasting of social media in teaching and learning, the teachers, campuses and the educators need to integrate social media tools as a learning resource and they must know to find out students attitudes towards public trust. Liu (2010) indicated that the result about social media as a learning tool that most students trust (94\%) social media policy and guidelines were trustable. The adoption of guidelines and policy are the most significant thing that campuses and teachers do, they are able to find the resources and talk to the scholars about the learning process. Besides, students, teachers and campus are able to communicate outside of the class and interact with each of them (p.106). The understanding about the issues that they are talking about on social media can help teachers or instructors to design activities meaningfully and use the 
Akselerator

Jurnal Sains Terapan dan Teknologi Vol.2 No.2 December 2017

tools effectively. The teachers and campuses create the future of learning which affecting students or people who interested in with an interest learning anticipate and prepare for change by highlighting the importance of participation by personal and collaborative media, smart networks and the creation of value through grassroots economics [29]. Furthermore, there are three indicate that social engagement is the top reason for social media adoption,

1. "It is followed by direct communication, which it is learning is not only in the classroom, but it is everywhere and takes 24 hours a day. If we ask some questions, it answers immediately with the comments,

2. It its quick feedback/ results about what the students want to learn, the feedback will be answered by the scholars or peers or scholars or someone in somewhere else,

3. relationship building, the students and teachers or scholars, staffs will build good relationships and whatever the students ask, it will answer immediately and it doesn't need to wait until the next class.

4. It is the ability to reach new friends who the other students or teachers or staff doesn't know." [30].

All this reflects social media networking establishment and interactive communication among networking members. The teachers, students and staffs' free input, about the questions that they want to ask about. Moreover, a new framework tailored for predictions regarding future good education system, professionalism for teachers which support the process of prediction are identified.

\section{Conclusion}

Social media as a platform is often seen as the key driver of communication which schools and teachers are established and utilized and engaged students in learning process with relevant and culturally diverse. It is understood that social media as a tool can be able to forecast for learning systems [31]. The impact of learning systems can benefit to the students with sense of community and the ability for students and teachers to share information with each other. Also, it engages students outside of school will increase goal achievements, and students will find their learning much more relevant and meaningful. Further use of social media has a natural collaborative element which students can critique, comment on each other's assignments, work in team to create content and can easily access each other and the teacher with questions. Facebook and Twitter are the most used of social media for students and teachers to engage learning process and communicate with others people outside the classroom although social media will never completely replace the classroom as one of the education systems. However, social media assists the educational practices while improving teaching efficiency and enhancing student learning experiences.[32]. As an effective way to increase students involvement and build better interaction skill, students become inspired by the technology such as internet, networking and students are taking more responsibility for their education, not only does it improve students' overall learning experiences, but also it helps students be on the cutting edge for competitive job market in their future [31]. Social media as the technology is emerging several ways to have important ability to use and apply the learning process for $21^{\text {st }}$ century of education.

\section{Bibliography}


Akselerator

Jurnal Sains Terapan dan Teknologi Vol.2 No.2 December 2017

[1] J. Seaman, "Social Media for Teaching and Learning," Always Learning Pearson, p. 6, 2013.

[2] J. Eaton, "e-Word-of-Mouth Marketing," Cengage Learning, pp. 1-7, 2012.

[3] M. Barakos, "Social Media and Forecasting: What is the potential of Social Media as a forecasting tool?," Copyright 2015, University of Twente,, Enschede, The Netherlands, 2015.

[4] K. S. Rekha and T. H. T.H.Sreenivas, "A Review on Run-Time Reconfigurations and Code Update Mechanisms in Wireless Sensor Networks," in International Journal of Innovative Research in Computer and Communication Engineering Vol. 3, Issue 2 , India, 2015.

[5] S. Asur and B. A. Huberman, "Predicting the Future With Social Media," 12 May 2014. 2014. [Online]. Available: https://www.researchgate.net/publication/45909086.

[6] M. W. Keran, "Economic Theory and Forecasting," National Bureau of Economic Research. (NBER), pp. 7-16, 1967.

[7] P. Gundecha and H. Liu, "Mining Social Media: A Brief Introduction," Tutorials in Operations Research, 1(4), pp. 1-17, 2012.

[8] L. Bridgestock, "What Drives Students' Social Media Usage?," 7 May 2013. [Online]. Available: https://www.topuniversities.com/blog/what-drives-students-social-media-usage.

[9] H. Rheingold, The Virtual Community: Homesteading on the Electronic Frontier., Reading, Massachusetts: Addison-Wesley. ISBN 0-201-60870-7 , 1993.

[10] A. M. Kaplan and M. Haenlein, "Users or the World, Unite! The Challenges and Opportunities of Social Media," Business Horison, pp. 53, 59-68, 2010.

[11] K. Hampton and e. al, "Social Media and the 'Spiral of Silence'," Washington, DC, 2014.

[12] A. Ratings, "Social Media and Forecasting: What is the Potential of Social Media as a Forecasting Tool?," 11 May 2015. [Online]. Available: http://www.alexa.com/topsites.

[13] H. Bockstette, "Social Media as a Source of Predictive Power to Forecast Market Needs," 5th IBA Bachelor Thesis Conference Copyright 2015, University of Twente, The Faculty of Behavioural, Management and Social sciences., p. 2, 2015.

[14] E. M. Rogers, Diffusion of Innovations, 3rd Edition, London: Macmillan Publisher, 1995.

[15] H. Rheingold, The Virtual Community: Homesteading on the Electronic Frontier (2nd Edition), Cambridge, Massachusetts: MIT Press. ISBN 0-262-68121-8, 2000.

[16] J. K. Dunbar, C. Reimers and R. Robertson, "Make Your Social Network A Learning Tool," 14 February 2014. [Online]. Available: http://www.clomedia.com/2014/02/14/make-your-socialnetwork-a-learning-tool/. 
Akselerator

Jurnal Sains Terapan dan Teknologi Vol.2 No.2 December 2017

[17] A. Craven, "Is Social Media the Future of University Education," 8 August 2014. [Online]. Available: https://socialmediaweek.org/sydney/2014/08/08/future-university-educationbegun/.

[18] T. Frey, "Future of Education," 3 March 2007. [Online]. Available: http://www.futuristspeaker.com/business-trends/the-future-of-education/.

[19] D. Mathias, "The Role of Social Media in Teaching and Learning," Seoul , 2012.

[20] N. Sclater, A. Peasgood and J. Mullan, "Learning Analytics in Higher Education," Jisc, Bristol, UK, 2016.

[21] A. Middleton and S. Beckingham, "Social Media for Learning: A Framework to Inspire Innovation," Smart Learning: Teaching and Learning with Smartphones and Tablets in PostCompulsory Education, pp. 46-56, 2015.

[22] C. Buddle, "THE VALUE OF USING SOCIAL MEDIA TOOLS IN TEACHING AND LEARNING," 6 September 2014. [Online]. Available: https://teachingblog.mcgill.ca/2014/09/16/the-value-ofusing-social-media-tools-in-teaching-and-learning/.

[23] C. H. F. e. a. Davis III, "Social Media in Higher Education: A literature review and research directions," SelectedWork, p. 8, 2012.

[24] J. C. Bertot, P. T. Jaeger and D. Hansen, "The impact of polices on government social media usage: Issues, challenges, and recommendations," Government Information Quarterly 29 , p. 30-40, 2012.

[25] S. Bernard, "How social media is changing education," Educational Publishers LLP trading as BBC Active, London, UK, 2010.

[26] I. Hovland, Knowledge Management and Organisational Learning: An International Development Perspective, London: Overseas Development Institute , 2003.

[27] J. Q. Anderson, "The future impact of the Internet on higher education: Experts expect moreefficient collaborative environments and new grading schemes; they worry about massive online courses, the shift away from on-campus life," Pew Research Center, p. 22, 2012.

[28] C. Redecker and Y. Punie, "The Future of Learning 2025: Developing a vision for change," European Commission, Joint Research Centre, Institute for Prospective Technological Studies (IPTS), pp. 3-17, 2013.

[29] G. Morgan, "Creating for Future of Learning," KnowledgeWorks Foundation, Palo Alto, CA, 2008.

[30] J. Maisch, "How to Predict the Future Using Social Media Monitoring," 2 February 2014. [Online]. Available: https://blog.digimind.com/en/author/jerome-maisch/. 
Akselerator

Jurnal Sains Terapan dan Teknologi Vol.2 No.2 December 2017

[31] J. Beidelman, "Social Media as an Educational Tool," 14 September 2015. [Online]. Available: http://blog.theeducationpartners.com/social-media-as-an-educational-tool.

[32] M. Blankenship, "How Social Media Can and Should Impact Higher Education," Education Digest: Essential Readings Condensed for Quick Review, 76 (7), pp. 39-42, 17 September 2011.

[33] M. Barakos, E. Constantinides and R. Loohuis, "Social Media and Forecasting: What is the Potential of Social Media as a forecasting tool?," in 5th IBA Bachelor Thesis Conference, Enschede, The Netherlands, 2015.

[34] D. M. Boyd and N. B. Ellison, "Social Network Sites: Definition, History and Scholarship," Journal of Computer-Mediated Communication, pp. 210-230, 2008.

[35] D. Witek and T. Grettano, "Teaching Metaliteracy: A New Paradigm in Action," Reference Services Review, Vol. 42, Iss. 2, pp. 188-208, 2014.

[36] P. Godwin, "Informaiton Literacy and Web 2.0: Is it just hype?," Program: Electronic Library and Information Systems, Vol. 43, No. 3, pp. 264-274, 2009.

[37] Y. Liu, "Social Media Tools as a Learning Resource," Journal of Educational Technology Development and Exchange, 3 (1),, pp. 101-114, 2010. 